\title{
Novel Metered Aerosol Valve
}

\author{
Amir Nourian ${ }^{1 *}$, Ghasem G Nasr ${ }^{1}$, Andrew J Yule ${ }^{1}$, Gary Hawthorne ${ }^{2}$ and Tom Goldberg ${ }^{2}$ \\ 1. Spray Research Group (SRG), Physics and Materials Research Centre (PMRC), School of Computing, Science \\ and Engineering (CSE), University of Salford, Salford, Manchester, UK \\ 2. The Salford Valve Company Ltd (Salvalco), Technology House, Salford, Manchester, UK
}

\begin{abstract}
The design and performance of a new valving mechanism for portable pressurized spraying devices is described, where the propellant in the device is a safe gas (so-called compressed gas) propellant rather than the current liquefied gases all of which are either volatile organic compounds or greenhouse gases. The valve sprays a fixed volume of liquid when the spraying actuator is depressed, as is essential used medical sprays, such as pressurized metered dose inhalers and nasal sprays, and also for automatic (wall-mounted) aerosol delivery systems for air-fresheners, insecticides and disinfectants. For 'compressed gas' aerosol formats, there is no flash vaporization of propellant so that pumping liquid from a metering chamber and atomization to form a spray must be achieved entirely by designing some means of using the pumping action of the gas in the container to act upon the liquid in the metering chamber. The new design utilizes a loosely fitting spherical piston element and a simple arrangement of a concentric housing and a moveable valve stem, such that liquid flow paths between the different elements are automatically closed and opened in the correct time sequence when the valve stem is depressed and released. Spraying data show excellent repeatability of liquid sprayed per pulse throughout the lifetime of device and drop sizes that are acceptable for devices such as air-fresheners and nasal sprays. The valve has only one additional component compared with liquefied gas metered valves and can be straightforwardly injection moulded. As will be explained, previous attempts failed due to expense, complexity and unreliability.
\end{abstract}

\section{Keywords}

Aerosol valve, spray metering, insert, inhaler, air-freshener

\footnotetext{
* Corresponding author: a.nourian@ salford.ac.uk
} 


\section{Introduction}

Significant contributing factors to world pollution are due to the use of liquefied hydrocarbon propellants for consumer aerosols and also hydrofluorocarbon (HFC) and hydrofluoroalkane propellants for medical sprays. Globally, there are around 20 billion consumer aerosol devices manufactured annually and the UK has an important share of this market [1] manufacturing five billion units which is second only to the USA.

Propellants used in aerosol cans have two categories: liquefied propellant, i.e. gases that are in the liquid phase at room temperature and pressure around 2-3 bar and higher, or, much less commonly, so-called compressed gas propellant, such as pressurized nitrogen, carbon dioxide, or air. One of the first popular propellants used in aerosol sprays was chlorofluorocarbon (CFC), such as trichlorofluoromethane (F11), dichlorofluoromethane (F12) and dichlorotetrafluoroethane (F14). CFCs were initially used as an aerosol propellant because they liquefy at low pressures and flash vaporize when leaving the can actuator, giving excellent atomization. They are also non-flammable, stable and low in toxicity and were thought to be extremely safe under normal conditions of use. However, this same stability means that they are not destroyed in the troposphere but instead drift upwards to the stratosphere, where they are broken down by the strong sunlight. This releases chlorine which adds to the natural depletion cycle of ozone. In the mid-1970s, the concern over their use led to the Montreal Protocol [2] that called for the elimination of CFCs and today all aerosol cans contain alternative propellants, such as liquefied petroleum gas and, for medical devices, HFCs.

Hydrocarbon propellants are VOCs and also highly flammable and are being increasingly subjected to legislation throughout the world. HFCs were also considered to be a replacement for CFCs; however, they contribute strongly to the greenhouse effect and are already controlled for non-medical applications, the most common use being as a sealed system refrigerant. Continued environmental pressures mean that the use of these liquefied gas propellants will almost certainly be banned. The only alternative chemically safe propellants, so-called compressed gas propellants, are not liquefied gases at the pressures usable in aerosol cans (up to 15 bar say), for example air and nitrogen. They do not flash vaporize as they leave the actuator, and this represents a number of challenges to the industry both for normal aerosol devices and metered aerosol devices, in particular:

1. For metered valve devices: flash vaporization is not available to pump liquid product from a metering chamber.

2. For all devices:

a. Atomization is more difficult due to the lack of rapid liquid-gas phase change as the product-propellant solution passes through the valve, actuator (the aerosol 'cap') and the 'insert' (the exit nozzle or atomizer).

b. For liquefied gas propellant, as a can empties more propellant is released to the gas phase so that can pressure remains reasonably constant. This does not occur for compressed gas propellant and can pressure reduces during can life, giving reduction in flow rate and increase in drop sizes.

Considering point 2 , to ensure comparable atomization quality and flow rate 'constancy' to liquefied gas propellants over the life of the can, research and development of a novel insert $[3,4]$ and valves [5,6] are of current interest. However, this paper addresses point 1, i.e. new valve designs for metered dose sprays that use compressed gas propellants, there being no such valves currently in the market. 


\section{Existing metered consumer aerosol and medical device valve designs}

Figure 1 shows a typical metering valve [7] used for airfresheners. Also, similar devices, with refinements and special materials, are used for medical spraying such as pressurized metered dose inhalers. For the former the valve is mounted on top of the metal 'cup' and the liquefied gas-liquid product (or suspension) is led to the valve by a polymer dip tube. For the latter the valve is at the bottom of the can so that the product (drug) and propellant can directly feed into the valve.

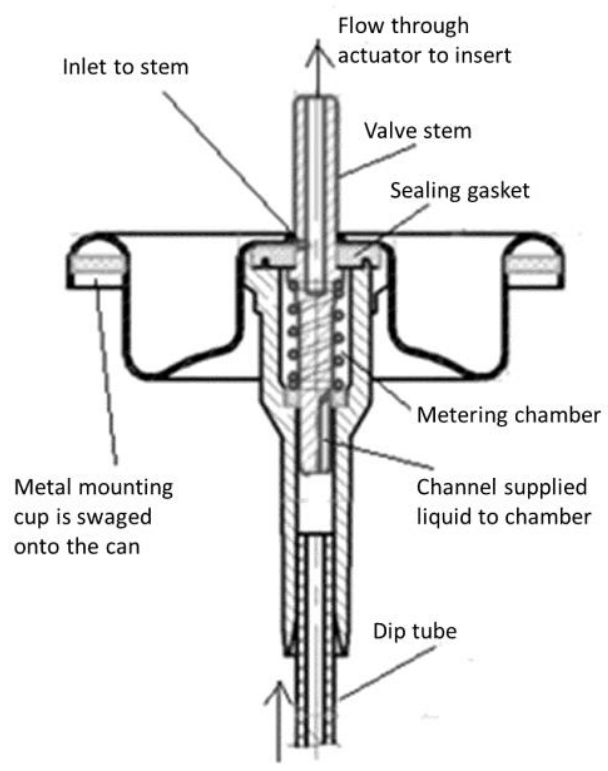

Figure 1: A typical metering valve using liquefied gas propellant.

Figure 2 shows the operating sequence [8] for the medical devices, which is essentially the same as that of the consumer aerosol. Referring to Figure 1 the concept is very simple: the cylindrical metering chamber is open to the solution of liquefied gas propellant and liquid product in the can via a dip tube. When the stem is depressed the lower part of the stem isolates the chamber from the dip tube so that a metered volume of product/liquefied propellant is isolated. There is an inlet hole in the side of the stem and with further depression of the stem this hole passes through the sealing gasket so that it is immersed in the liquid in the metering chamber. The inlet hole is linked to the exit of the 'insert' (the atomizer nozzle) by a fluid pathway through the stem and actuator cap. Thus, the metering chamber is exposed to the atmosphere via the inlet hole and the pressure drop causes the flash vaporization of some of the liquefied gas in the chamber. The resulting gas release causes the liquid in the chamber to be pushed out through the insert and thus form a spray. The spray formation is also enhanced by this phase change of the propellant to gas which is completed during the flow through the insert and just downstream. The stem can be kept depressed, but no further fluid leaves the can once the metering chamber is empty. Releasing the stem allows the chamber to refill. 


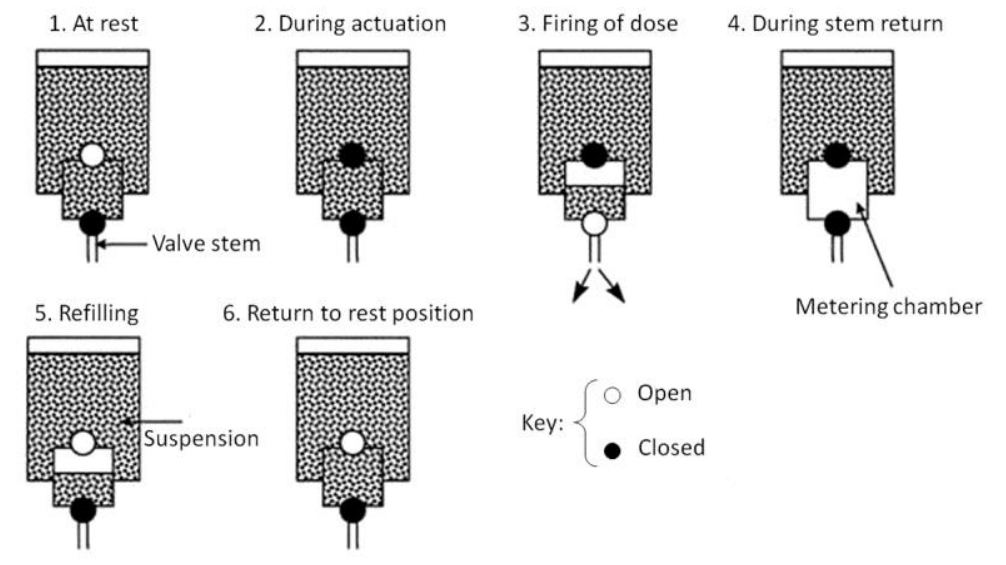

Figure 2: Sequence for a metering valve using liquefied gas propellant

If the conventional metering valve were used with a compressed gas propellant, the metering chamber would fill only with the liquid product. This being incompressible, when the stem is depressed there would be no pressure energy to push the liquid from the chamber, i.e. the valve would not function at all. Clearly a new type of valve is required that uses a means of pumping the metered volume from the chamber and the only energy source for doing this is the pressure energy of the compressed gas in the can. There are many patents on metering valves for 'flashing' propellant aerosols (butane, HFC, etc.) but apart from details of the methods of opening and closing orifices in the valves, they are not relevant to the compressed gas case. For compressed gas metering valves, designs must pump the liquid from the metering chamber either by using a separate small chamber storing some of the gas, by some piston arrangement or by using a chamber with flexible sides that is compressed by the liquid or gas outside the metering chamber. There are several attempts to solve this problem including a method9 of bleeding off some of the gas from the can into the chamber in order to force the liquid from the metering chamber. A difficulty here is that this depletes the gas pressure in the can and it is also unclear that sufficient energy is thus obtained to ensure adequate atomization over the life of the spray. Among the prior articles which recognizes that the can pressure must be used in order to force the liquid from the metering chamber are examples where the metering chamber is partly enclosed by an 'elastomeric sleeve' $[10,11]$ which transmits the pressure of liquid in the reservoir to the liquid in the chamber. A similar concept has been described [12] that uses collapsible bellows. These devices are not currently manufactured, probably because of cost and the need for critical materials. A range of designs involving pistons activated by the can gas have been described $[13,14]$. These types of design have not been manufactured for aerosol devices again due to cost but also because of the friction of the pistons that required spring loading and would be complex and unreliable. Table 1 gives an overview of the most relevant patents in the field and it is seen that interest in the problem extends back more than 50 years. There is currently no metering valve available suitable for consumer aerosols or medical sprays when using compressed gas propellant. A suitable valve must have both low unit cost and reliability, and the aim of the work here was to develop and prove the performance of such a valve. 


\begin{tabular}{|c|c|c|c|}
\hline Date & Brief title & $\begin{array}{c}\text { First named } \\
\text { inventor/company }\end{array}$ & Notes \\
\hline 1962 & $\begin{array}{l}\text { Metering valve } \\
\text { US3018928 }\end{array}$ & Meshberg & $\begin{array}{l}\text { Various arrangements of spring- } \\
\text { loaded pistons displace liquid }\end{array}$ \\
\hline 1965 & $\begin{array}{l}\text { Valve mechanism with } \\
\text { metering ball. } \\
\text { US3169677 }\end{array}$ & $\begin{array}{c}\text { Focht/Precision Valve Corp New } \\
\text { York }\end{array}$ & Ball inserted in dip tube \\
\hline 1965 & $\begin{array}{l}\text { Metered aerosol valve, } \\
\text { compressed gas } \\
\text { US3394851 }\end{array}$ & Gorman/Sterling Drug & $\begin{array}{l}\text { Bleeds gas into separate metering } \\
\text { chamber, and this is used to pump } \\
\text { out metered liquid. }\end{array}$ \\
\hline 1989 & $\begin{array}{l}\text { Metering valve } \\
4809888\end{array}$ & Bret/ SPRIT France & $\begin{array}{l}\text { Contains piston and elastic } \\
\text { membrane over "valve head" }\end{array}$ \\
\hline 1990 & $\begin{array}{l}\text { Metering valve for } \\
\text { dispensing aerosols } \\
\text { US4953759 }\end{array}$ & Schmidt/ Vernay labs & $\begin{array}{l}\text { Uses "wall of resilient material" } \\
\text { to enclose the liquid metering } \\
\text { chamber that collapses like a } \\
\text { balloon when valve depressed }\end{array}$ \\
\hline 1991 & $\begin{array}{l}\text { Dispensing pressurised } \\
\text { containers } \\
\text { US5037013 }\end{array}$ & Howlett/ Bespak plc UK & $\begin{array}{l}\text { "Collapsible chamber metering } \\
\text { valve" using elastomeric sleeve. } \\
\text { Similar to } 4953759 \text { (1990). }\end{array}$ \\
\hline 1995 & $\begin{array}{l}\text { Metering valve for } \\
\text { aerosols } \\
\text { WO 95/11841 }\end{array}$ & Sullivan & $\begin{array}{l}\text { Valve using bellows "so no } \\
\text { sliding seals" and "good for } \\
\text { powder containing liquid". }\end{array}$ \\
\hline 2003 & $\begin{array}{l}\text { An aerosol type } \\
\text { dispenser } \\
\text { EP } 1283180 \text { A2 }\end{array}$ & Oshima/ Mitani valve Co Japan & $\begin{array}{l}\text { Separate chamber stores gas to } \\
\text { evacuate metered liquid. }\end{array}$ \\
\hline
\end{tabular}

\section{Materials and Methods}

New metered valve design

Design requirements: The design of a new metered aerosol valve had the following constraints, these not having been met by previous attempts at designing such valves. Reference is made to the consumer aerosol case, but most factors also apply to medical sprays, together with more stringent requirements regarding materials and reliability:

1. The valve must have a minimum number of components above those used in existing liquefied gas metered valves, i.e. currently a housing, stem and gasket seal.

2. The valve must be able to manufacture from polymer by injection moulding (this has repercussions on for example the need to avoid re-entrant shapes so that tools may be extracted).

3. The valve must be compatible with standard consumer aerosol components: the cup, actuator cap, inserts (the atomizer nozzles), gasket seal, dip tube and can.

4. It should be capable of being mass produced using standard aerosol industry assembly machinery.

5. Rapid filling of cans should be possible using standard aerosol industry machinery. 
6. Regarding the performance of the valve, with suitable actuator and insert:

a. It should be capable of spraying metered volumes ('spray pulses') of aqueous or ethanol-based liquids, in a range of at least $5-100 \mathrm{~mm}^{3}$, typical for consumer aerosol and medical applications: the metered volume being simply controllable by minor component modification.

b. It should have acceptable pulse-to-pulse variation of volume sprayed, preferably less than $5 \%$.

c. The volume sprayed should have a similar steadiness during the lifetime of the device.

d. For the main application of the valve in metered air-fresheners, drop sizes should be in the approximate range $40 \mu \mathrm{m} \leq \mathrm{D}_{\mathrm{v} 50} \leq 80 \mu \mathrm{m}$, by consideration of the performances of current non-metered compressed gas air-fresheners. For example, Proctor and Gamble 'Febreze' a market leading product, aqueous based, propelled by nitrogen.

Initial consideration of design: In order to understand the valve design process, it is useful to propose the sequence for a compressed gas valve for the case where the metered liquid volume is pushed from the valve via a piston that is in turn pushed by pressurized liquid in the can. Such a sequence is shown in Figure 3 where (i) shows the 'at rest' condition where the device is awaiting activation by depressing the stem (usually by an electronic actuator device).

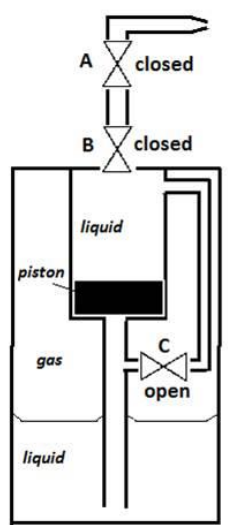

(i)

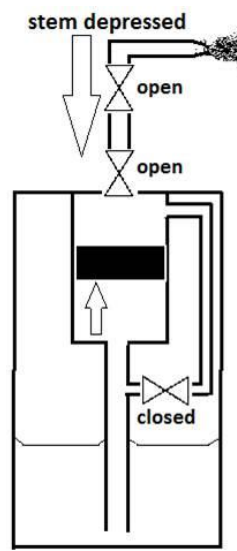

(ii)
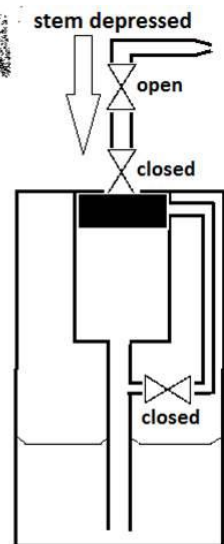

(iii)

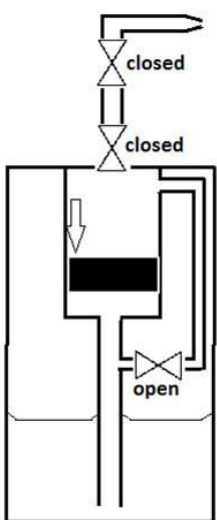

(iv)

Figure 3: A sequence for a metering valve using compressed gas propellant

Three 'sub-valves' forming the overall valve are indicated: valve $\mathrm{A}$ is in fact a conventional stem hole-sealing gasket valve, similar to that shown in the upper part of Figure 1, valve B has to be sequenced such that it switches on when the metered volume is to be sprayed and switches off immediately that volume has been sprayed, and valve $\mathrm{C}$ is used to refill the metered volume after spraying has completed, it could be open (as shown) or just have closed at this time. Valves A and B feed the fluid path in the actuator to the atomizer nozzle (the 'insert' as it is termed in the aerosol industry) and they are both shown closed in Figure 3(i). The metered volume is that volume of liquid above the piston (shown here schematically as a cylindrical shape but other shapes are possible) that is swept by the upper surface of the piston. The lower part of the piston is exposed to the high-pressure liquid in the can via the dip tube. In Figure 3(ii) the situation is shown shortly after the stem has been depressed. Both valves A and B must 
open on depressing the stem, and valve $\mathrm{C}$ must be closed so that the fluid path above the metering chamber is exposed to atmospheric pressure via its exit at the insert. The pressure difference across the piston causes it to move upwards and spraying is in progress. This proceeds until the situation in Figure 3(iii) is reached where the piston reaches its upper limit and at this point valve B must be closed. Thus, even though the stem may continue to be pressed downwards there is no further spraying: an essential feature of a metering aerosol valve. At some time, the depression of the stem will be removed by the actuator device so that valve $\mathrm{A}$ will be closed, and valve $\mathrm{C}$ can then open so that the metering chamber can refill. Figure 3(iv) shows the situation during the refilling process, which must be achieved before the next depression of the stem occurs.

The above description raises various questions including:

1. How should valves $\mathrm{B}$ and $\mathrm{C}$ be designed?

2. How can they be activated at the correct times?

3. Are there problems with sticking and friction with the piston and what is the best piston shape and material?

4. How is the piston returned to the bottom of the metering chamber?

5. How can such a valve design satisfy the requirements listed earlier, particularly the need for simplicity, low cost and minimal components?

The next Section explains how the new design addresses these questions.

The new valve design: The design process went through many stages and only the final result is shown here. The design shown is capable of manufacture in just two components (the stem and housing) by injection moulding and where the only additional component, compared with current liquefied gas propellant metered valves, is a 'piston element'. As described in patents covering the valve $[15,16]$ a key and novel step in the design evolution is the positioning of the metering chamber inside the stem. This is shown in Figure 4 which shows axial sections of the valve at two times in its operating sequence. This positioning of the metering chamber greatly simplifies the design and requires only two components to be made by injection moulding. 


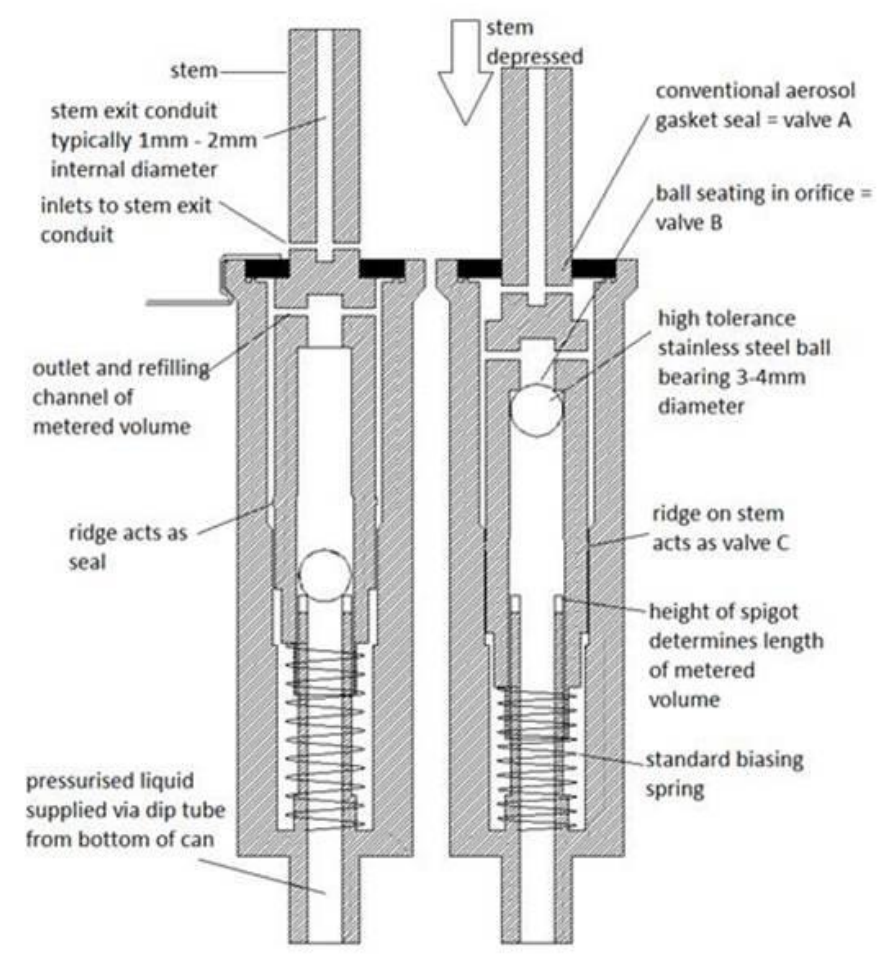

Figure 4: The new compressed gas metered valve: (left) at rest primed and (right) stem depressed and full metered volume sprayed

Figure 4 (left) illustrates an axial section of the metered valve, where the central valve member (valve stem) is in its normal rest position. The valve stem is at this full movement, vertically upwards, and the spherical piston is at its fully downwards position, the metering chamber is fully charged with liquid. Figure 4 (right) shows the valve where the valve stem has been fully depressed downwards and the metering chamber has been fully evacuated of liquid, as can be seen with the spherical piston in the fully upward position.

The operation of the metering valve is clear if reference is made to the above description of Figure 3 and, as indicated on Figure 4, the valves $\mathrm{B}$ and $\mathrm{C}$ within the metering valve are understood. Valve B, which seals the upper part of the metered volume chamber when all the liquid is sprayed, is formed by the spherical metal ball (which acts as the piston) when it seats in an orifice. Valve $\mathrm{C}$ is formed by a ridge on the outside of the stem that forms a sliding interference fit with the interior of the housing when the stem is depressed so that the ridge is in the narrower lower part of the housing. This use of a ridge integral to the stem is very advantageous because the ridge can be made as part of the injection moulding process of the stem and it avoids the cost of a separate sealing element such as an O-ring.

Note that when the aerosol is not in active cycle the interference fits are not therefore required in order to refill the metered dosage of the liquid in the chamber. Moreover, the new design of metered valve that was described earlier is effectively removing the requirements for the corresponding valve $\mathrm{B}$ and $\mathrm{C}$ that are shown in Figure 3. The use of a spherical piston element is another key feature for several reasons: 
1. High tolerance stainless steel ball bearings are mass produced in many sizes and with very low unit cost.

2. Assembly of the ball in the stem is straightforward as there is no orientation requirement.

3. There is less potential for jamming inside the chamber than for cylindrical or conical piston elements.

4. The high density of the steel allows the use of gravity to return the ball to the bottom of the metering chamber, as described in more detail below.

During development of the device, interesting and useful features of the use of the spherical piston balls became clear. There was an initial concern that it would be necessary for the ball to be quite a tight fit inside the chamber in order to transmit force to the metered liquid without leakage and this would cause friction problems and also problems with returning the ball to the bottom of the chamber, probably by a spring system. This would cause complexity and also a loss of pressure at the insert and thus poor atomization. However, as described in the next Section, it was found to be satisfactory to have the ball as a loose fit inside the channel, with a gap around the ball of $0.1-0.2 \mathrm{~mm}$. This allowed the ball to fall back down the metering chamber entirely due to gravity in a few seconds.

Installation of the new metering valve in commercial aerosol products: The device is designed to operate in the vertical, or near vertical, orientation, but this is not a restriction for most applications. The valve is shown in Figure 5 mounted in the top of a standard aluminium or steel container (can), where it would have the top part crimped into a metal cup of the aerosol can in the conventional manner: the can, dip tube, sealing gasket, cup and the dimensions of the upper 'turret' of the valve are of standard sizes in common usage in the aerosol can, valve and actuator industry.

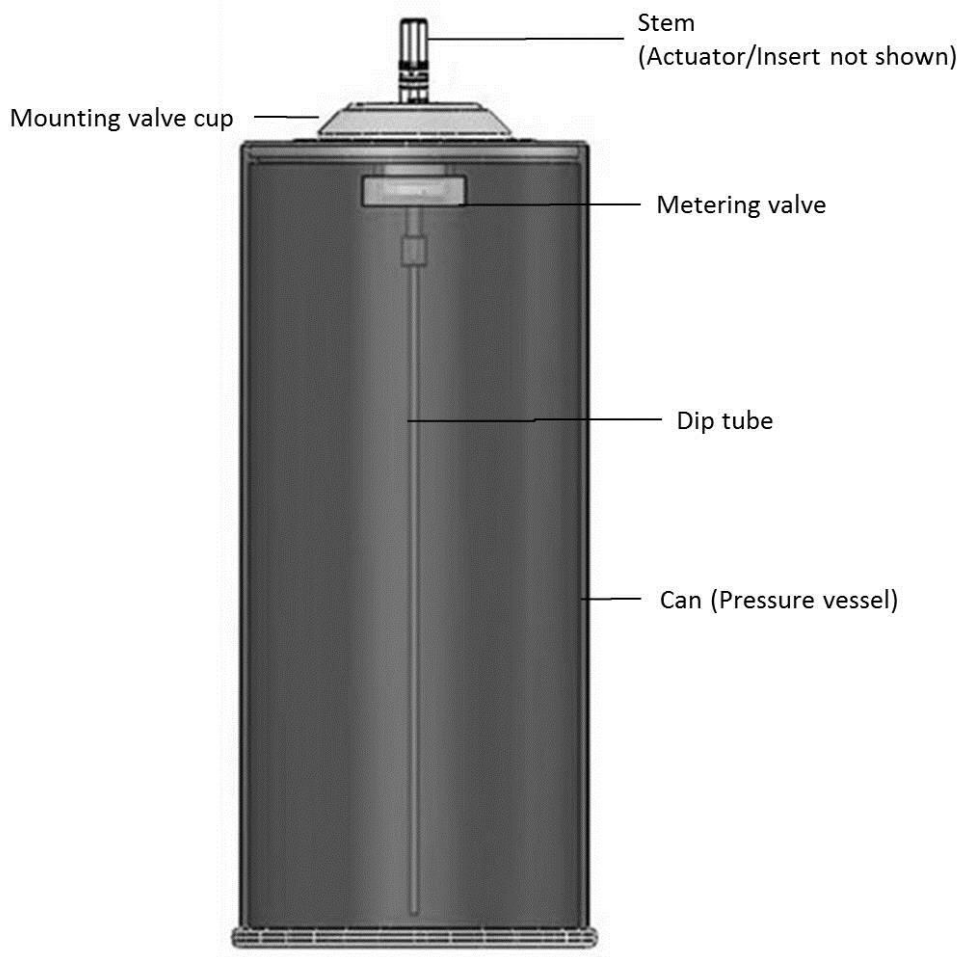

Figure 5: Valve assembled within a can 
The upper part of the valve stem can also be one of the standard dimensions in current usage, so that commercially available actuator caps and spraying nozzles (inserts) can be fitted on to it. An automatic electrical actuator depression system would normally be used, as shown in Figure 6, as part of a wall or shelf mounted aerosol for air-fresheners or insecticides.

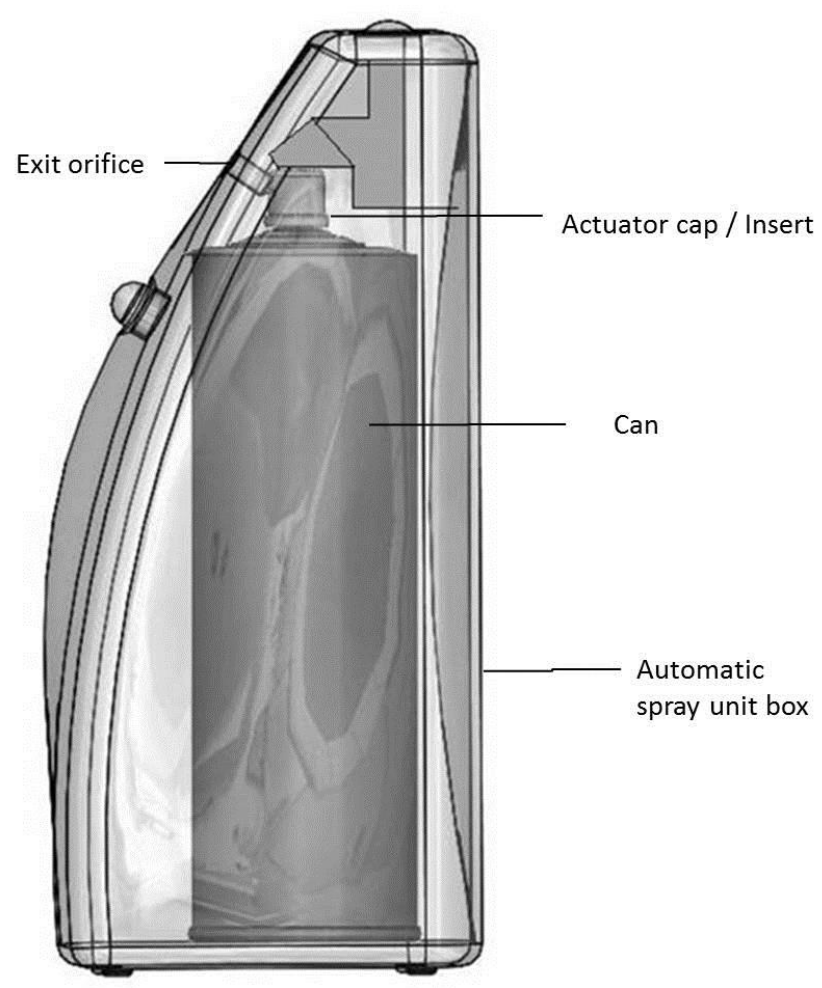

Figure 6: Aerosol can mounted in automatic spray unit

A standard compressed gas format aerosol can is used with aqueous or ethanol-based liquid product in the container and air or nitrogen gas (propellant) pressurizing the container. Air can be used if there are no potential problems due to flammability of product or bacterial growth. There are regulations and guidelines regarding the design, pressures, filling and safety of such systems, determined in Europe by the European Commission and described in various parts of the Aerosol Dispensers Directive [17] see also the websites of the European Aerosol Federation (Paris) and British Aerosol Manufacturers Association (London). Current filling pressures are mainly in the range $4-10$ bar $\left(\right.$ at $20^{\circ} \mathrm{C}$ ) although cans safe up to 18 bar or more are available: For compressed gas aerosols, the higher the initial can pressure, the smaller the drop size that can be produced. Guidelines for liquefied gas propellant sprays specify the initial can fill ratio, volume of liquid/actual volume of gas in the can, to be at least $60 \%$. However, this can be relaxed for compressed gas propellants to recognize the dropping off of can pressure during spraying. This pressure reduction is less if the initial fill ratio is lower and it is generally accepted that a $50 \%$ fill ratio is acceptable for compressed gas aerosol formats.

When using liquefied gas propellant the atomization process is dominated by the flash vaporization of the propellant inside the insert and this is essentially a two-fluid (high velocity 
gas-lower velocity liquid) atomization process, known [18] to be excellent for fine atomization. Therefore, a simple orifice can often be used for the insert. However for compressed gas propellant, where a single phase liquid flows through the insert without a change in phase, the design of the atomizer insert is critically important and the most suitable device is a miniature swirl atomizer. This causes liquid break up by forming a thin conical liquid sheet for the emerging jet that then breaks up via waves and perforations into a well atomized spray [18]. In the consumer aerosol industry, these miniature swirl atomizer inserts are mass produced by injection moulding of polymer and known as mechanical break up units (MBUs). They are used for all compressed gas aerosols and many liquefied gas propellant aerosols. Figure 7 shows views of a typical MBU of the type used with the metered valve and Figure 8 shows how the MBU insert is connected to the exit of the actuator cap.

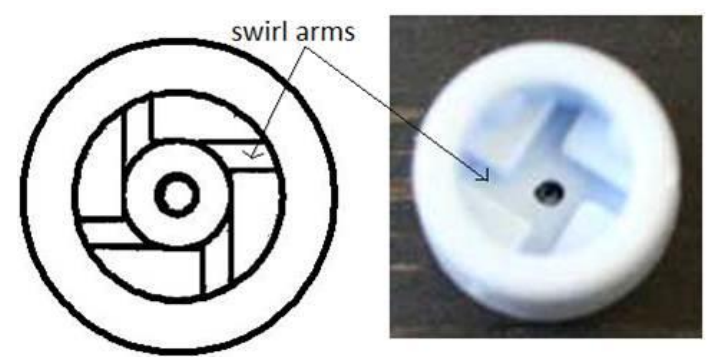

Figure 7: Sketch and photograph of a typical miniature swirl atomizer (MBU) with an exit orifice of $0.33 \mathrm{~mm}$ diameter

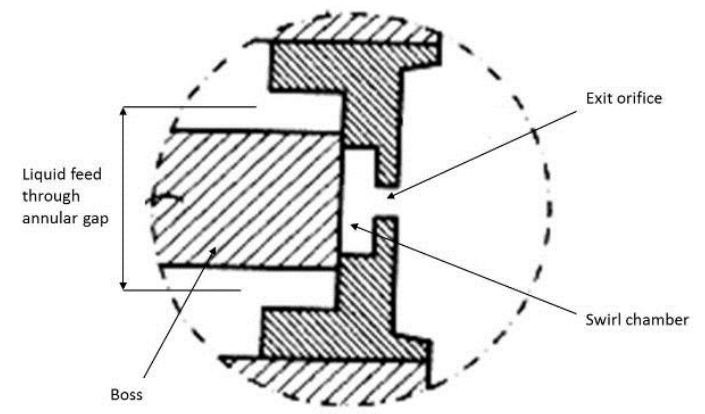

Figure 8: Cross section of a typical MBU insert about to be pushed onto the boss on the actuator cap

\section{Performance and testing procedure of the new metered valve}

Experiments were carried out both to test the reliability and spraying performance of the new valve and also to make comparisons with a commercial liquefied gas propellant metered valve. The case of air-fresheners was chosen and in particular the new valves were mounted in compressed gas (air) filled cans that were similar to the liquefied propellant refill cans for the freshmatic automatically actuated system, for example the freshmatic system of Reckitt and Benckiser Plc (Hull, UK). The new compressed gas valve cans could thus be mounted in the automatic actuator as shown in Figure 6. The metered valve was inserted into a standard aerosol can and was filled with $150 \mathrm{ml}$ of distilled water and compressed with air to a pressure of 12 bar (gauge). The fill ratio for the can was $50 \%$. A standard precision valve orifice MBU insert with a $0.33 \mathrm{~mm}$ exit orifice was used for the tests, this being common for airfresheners.

The liquefied gas and compressed gas cans were both manually sprayed for 80 bursts prior to insertion into the actuator box (Figure 6). This was to ensure that both were operating satisfactorily and also to avoid any starting up effects (no significant effects appeared to occur). The spray pulse setting was set to $8 \mathrm{~g} / \mathrm{day}$, according to the device data sheet, which would provide $120 \mathrm{~g}$ over 15 days and nearly empty the cans. It is noted that this is an unusually high 'dosage rate', chosen to ensure that the experiments were not unduly long. The metering chamber of the freshmatic valve provided nominally a product delivery of $0.05 \mathrm{~g}$ per burst so that the compressed gas valve metering chamber was made with a volume $0.05 \mathrm{ml}\left(50 \mathrm{~mm}^{3}\right)$. It is noted that the compressed gas valve was used with distilled water whilst the commercial system sprayed a solution of aqueous-based product and liquefied gas (mainly butane). 
At periodic intervals, after a number of spray pulses, the droplet size, can pressure and flow rate were measured. A laser instrument was used to measure the droplet size distributions of the sprays produced at a distance of $200 \mathrm{~mm}$ from the insert exit to the laser beam. This instrument measures the angular distribution of forward scattered light and converts this into the volume distribution of droplets [18].

Can pressure was determined to be within \pm 0.1 bar by using a purpose-built Bourdon gauge for aerosol cans that fitted onto the stem, after removal of the actuator cap. The mass or volume sprayed was determined by weighing the cans at intervals to an accuracy of $\pm 0.01 \mathrm{~g}$. Digital still and video images of the sprays were also taken at intervals.

\section{Results and discussion}

Figure 9 compares the appearances of the liquefied gas and compressed air propellant spray pulses, when they have penetrated to approximately $150 \mathrm{~mm}$ downstream. The cone angle for the compressed gas spray is approximately $30^{\circ}$ compared with approximately $20^{\circ}$ for the liquefied gas propellant spray.

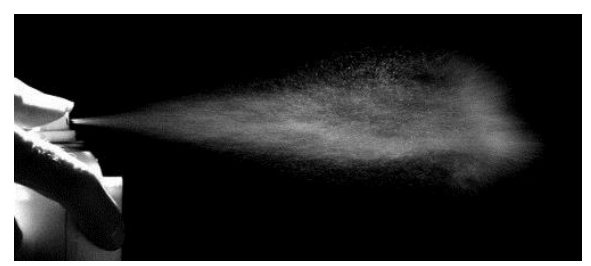

(a)

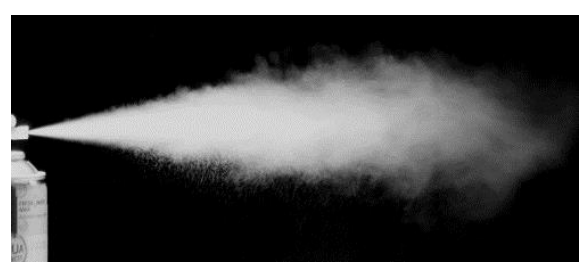

(b)

Figure 9: Spray pulses from (upper photograph) new metered valve using water (compressed air propellant), and (lower photograph) commercial freshmatic air-freshener with conventional liquefied gas valve (mainly butane propellant).

This is expected because the swirl atomizer (MBU) inevitably gives an angle of around $30^{\circ}$ or larger due to the formation of an initial conical liquid sheet. There is no evidence of 'drop out' of larger drops from the compressed gas propellant spray, which would obviously be undesirable. The higher level of reflected light from the liquefied gas propellant spray near the insert is explained by the existence of very fine hydrocarbon droplets and vapour there. For the $0.33 \mathrm{~mm}$ MBU insert, a typical spray pulse duration is $50-100 \mathrm{~ms}$.

Note that in this Figure, the denser the spray the whiter the image could normally be portrayed and this seems to be there are fine particles which are occupied within the spray. However, this is largely due to the reflection of the light onto the emerging spray as well as the presence of the tiny droplets of HFC (butane), rather than the actual aqueous-based product droplets.

As can be seen in Figure 10 for the conventional metered valve case, a relatively constant pressure is maintained over the life of the can. This is due to the continual release of new vapour phase inside the can as liquid hydrocarbon and liquid product are released from the can during spraying. As expected for the compressed gas propellant case, the can pressure reduces from 12 to 5.5 bar: for a $50 \%$ fill ratio the air in the can doubles in volume as the can empties so that for isothermal expansion (which is effectively the case) the absolute pressure reduces from $(12+1)=13$ to $6.5 \mathrm{bar}(\mathrm{abs})$, giving $5.5 \mathrm{bar}$ (gauge). 


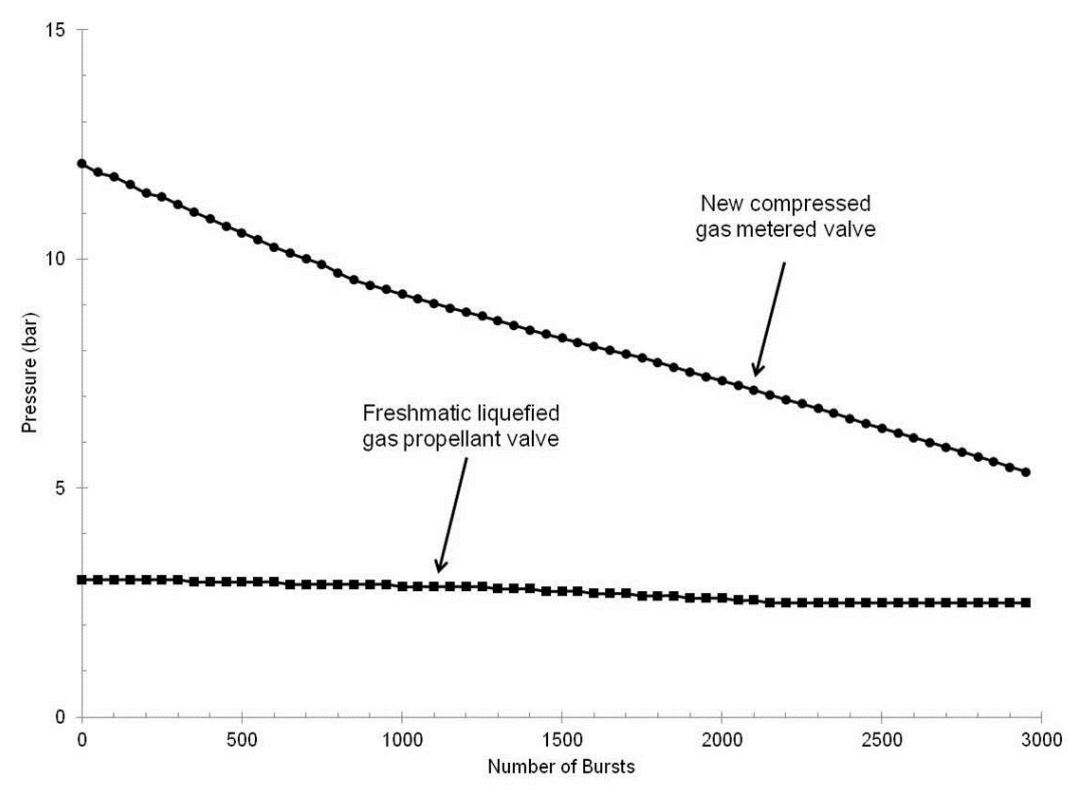

Figure 10: Pressure comparison between conventional metered valve and the compressed air valve

Figure 11 shows the weight of liquid left in the can as a function of the number of spray pulses for the two cases. The linearity of the compressed gas valve case is excellent and processing the data further showed that the volume sprayed per pulse is always within $5 \%$ of the design value $0.05 \mathrm{ml}$. The volume sprayed per pulse by the liquefied gas propellant valve is slightly more, giving a steeper gradient, but this is expected because the specified volume was a nominal indication.

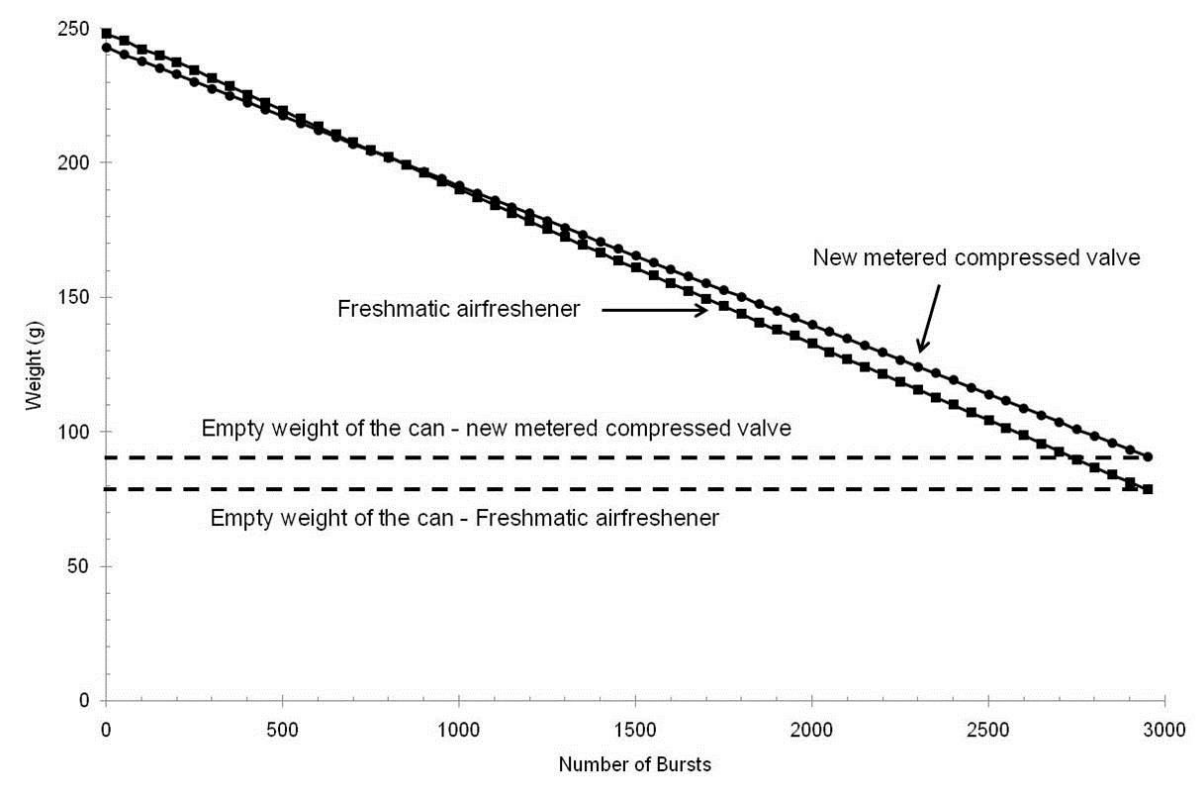

Figure 11: Performances of a conventional and compressed gas metered aerosol valves: volumes remaining in cans over two days of activations

In fact the linearity of the liquefied gas case is poorer than the compressed gas case, showing that the new valve gives more consistency in performance than the conventional liquefied gas 
valve. The results confirmed that the relatively loose fit of the ball 'piston' in the new valve had no significant adverse effect on the consistency of metering. Figure 12 shows drop size data where the drop diameter shown is the volume median diameter $\mathrm{D}_{(\mathrm{v}, 50)}$ which is the diameter above and below which $50 \%$ of the local spray lies, by liquid volume.

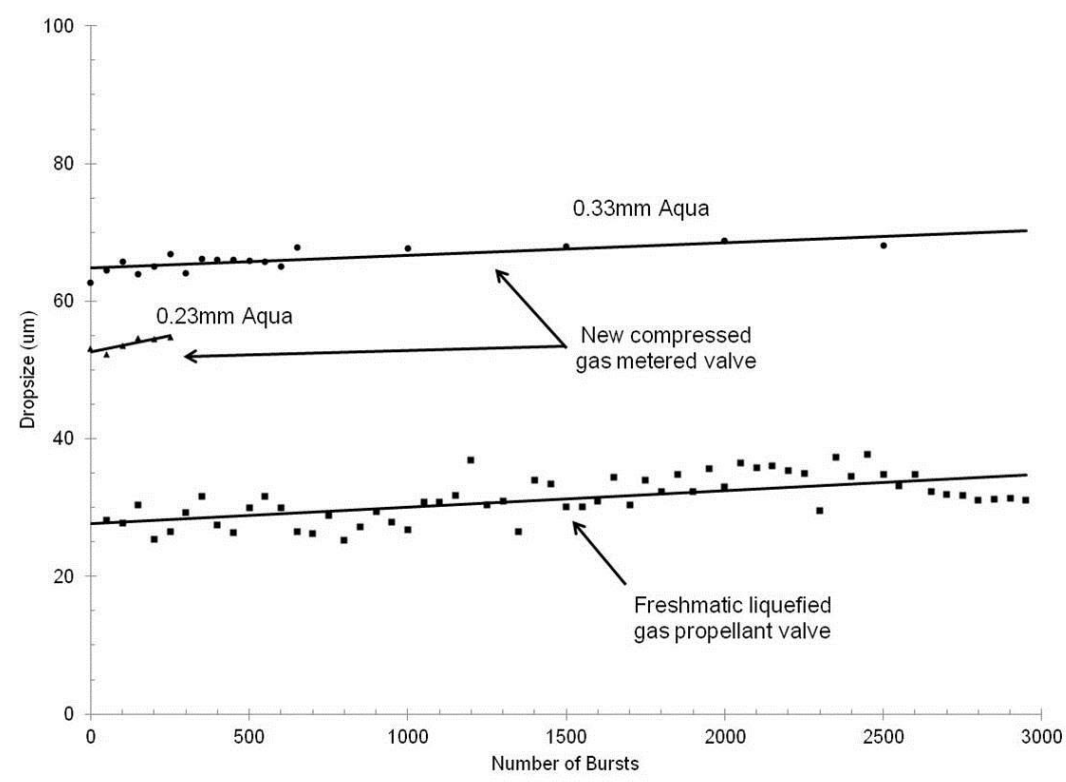

Figure 12: Droplet size comparison between the new compressed air valve and conventional liquefied gas valve (freshmatic air-freshener)

This is the most commonly used diameter in the consumer aerosol industry to represent the droplet size. This is mainly due to the fact that if an average diameter-based number of droplets are used, instead of the volume median diameter $\mathrm{D}_{(\mathrm{v}, 50)}$, the corresponding resulting distribution can therefore exclude the weighting effect of the larger drops within the spray. As expected the diameters for the compressed gas case are significantly larger than those for the liquefied gas valve, but they are still in an acceptable range of 60-80 $\mu \mathrm{m}$. In fact, a reduction in diameter can be achieved by using an MBU swirl atomizer insert with a smaller exit orifice. An exit orifice diameter of $0.23 \mathrm{~mm}$ is amongst the smallest in common use and some repeat tests using an MBU with this exit diameter were carried out for 500 spray pulses. As shown in Figure 12 there is a significant reduction to values closer to those of the liquefied gas propellant case.

In addition, the use of smaller swirl atomizer can be beneficial in providing smaller drop size and thus finer particles without any effect on the mass production during commercialization of the valve with the chosen swirl atomizer insert and actuator. 


\section{Conclusions}

- The metered valve aerosol device presented in this paper enables compressed air propellant to be used in consumer aerosol devices in place of less environmentally friendly hydrocarbon propellants.

- Key design innovations including the use of a ball as a piston in the metering chamber, and positioning this chamber inside the valve stem, led to two straightforward injection moulded components.

- The device was trialled over extended periods and performance was compared with a current consumer air-freshener product, showing that the device delivered excellent metering consistency over the life of the can. The droplet size produced is larger than for commercial liquefied gas propellant products, but it is acceptable for air-freshener devices.

- The same basic type of metered valve also has medical applications, particularly for nasal sprays.

\section{Declaration of Conflicting Interests}

The author(s) declared no potential conflicts of interest with respect to the research, authorship, and/or publication of this article.

\section{Funding}

The author(s) disclosed receipt of the following financial support for the research, authorship, and/or publication of this article: The authors wish to thank Salvalco Ltd for their financial support and all the team at University of Salford for their constant support and encouragement throughout this investigation.

\section{References}

1. Annual Report, British Aerosol Manufacturers Association, Smith Square London, 2006.

2. The Montreal Protocol on Substances that Deplete the Ozone Layer, Ozone Secretariat, United Nations Environment Programme, 1987 (adjusted London 1990, Copenhagen 1992, Vienna 1995, Montreal 1997, Beijing 1999), United Nations Environment Programme, Nairobi, Kenya, 2000.

3. Clark PA and Valpey RS. Aerosol dispenser system having VOC-free propellant and dispensing mechanism thereof. US Patent application 20090020621, S.C. Johnson and Son Inc., 2009.

4. Nasr GG, Yule AJ and Burby ML. Spray discharge assembly with fluid jets directed against sharp edge. United Kingdom Patent GB2475422A, 2012.

5. Nasr GG, Yule AJ and Burby ML. Aerosol spray device having a valve which generates bubbly flow. United Kingdom Patent GB2479609A, 2011.

6. Nasr GG, Yule AJ and Burby ML. Aerosol spray device with valve arrangement having low coefficient of loss. United Kingdom Patent GB2475393A, 2011.

7. Yingbo Aerosol Valve Co, Zhongshan, China, http:// www.yingbo-valve.com, 2013.

8. Brindley A. The chlorofluorocarbon to hydrofluoroalkane transition: the effect on pressurized metered dose inhaler suspension stability. J Allergy Clin Immunol 1999; 104: 221-226.

9. Gorman WG. Metered aerosol valve for use with compressed gas. Patent US3394851, 1965.

10. Schmidt WJ. Metering valve for dispensing aerosols. Patent US4953759, 1990. 
11. Howlett DJ. Dispensing apparatus for pressurized dispenser containers. Patent US5037013, 1991.

12. Sullivan MH. Metering valve for aerosols. Patent WO 95/1184, 1995.

13. Meshberg P. Metering valve. Patent US3018928, 1962.

14. Bret P, Pozzi J and Suck C. Metering valve. Patent US4809888, 1989.

15. Nasr GG, Yule AJ and Burby ML. Liquid dispensing apparatus. Patent WO $2011042751,2011$.

16. Nasr GG, Yule AJ and Burby ML. Liquid dispensing apparatus. Patent WO $2011042752,2011$.

17. Pressure equipment and gas appliances, Aerosol Dispensers Directive (ADD), European Commission, Brussels, Amendment 2008/47/EC, 8 April 2008.

18. Nasr GG, Yule AJ and Bendig L. Industrial sprays and atomization. London: Springer Verlag, 2004. 